\title{
Adjuvant Endocrine Therapy in Pre- and Postmenopausal Patients
}

\author{
Christian Jackisch $^{\mathrm{a}^{*}}$ Andreas Schneeweiss ${ }^{\mathrm{b}^{*}}$ \\ ${ }^{a}$ Klinik für Gynäkologie und Geburtshilfe, Klinikum Offenbach, \\ bUniversitäts-Frauenklinik Heidelberg, Germany
}

\section{Key Words}

GnRHa - Tamoxifen - Premenopause - Postmenopause . Aromatase inhibitor - Adjuvant therapy - Breast cancer, endocrine responsive

\section{Summary}

The treatment rationale in endocrine responsive breast cancer, based on the individual risk of relapse, consists either of endocrine therapy alone or a chemoendocrine treatment. Tamoxifen as an antiestrogen given for 5 years is still the mainstay in premenopausal women. In women with ovarian function the use of $\mathrm{GnRHa}$ for 2-3 years is recommended. Monotherapy either with $\mathrm{GnRHa}$ or aromatase inhibitors (Al) should be avoided. The combination of $\mathrm{GnRHa}$ and $\mathrm{Al}$, however, is subject of ongoing clinical trials. Adjuvant therapy for postmenopausal women with endocrine responsive breast cancer should include an Al. However, neither the optimal timing nor duration of Al therapy is established. Treatment options include i) 5 years of anastrozole or letrozole treatment instead of tamoxifen, ii) sequential therapy consisting of tamoxifen for 2-3 years followed by exemestane or anastrozole for the remainder of 5 years, or iii) sequential therapy consisting of tamoxifen for 5 years followed by letrozole for 5 years. The late consequences of $\mathrm{Al}$ therapy, including osteoporosis and fractures, should be considered.

\author{
Schlüsselwörter \\ GnRHa - Tamoxifen · Prämenopause · Postmenopause · \\ Aromatasehemmer - Adjuvante Therapie . \\ Mammakarzinom, endokrin sensitives
}

\section{Zusammenfassung}

Die Therapie des endokrin modulierbaren Mammakarzinoms besteht risikoadaptiert entweder aus einer reinen antihormonellen Therapie oder einer sequentiellen chemoendokrinen Therapie. In der Prämenopause kommt eine 5-jährige Blockade des Östrogenrezeptors durch Antiöstrogene vom Typ Tamoxifen zum Einsatz. Diese Therapie sollte bei vorhandener ovarieller Aktivität für die Dauer von 2-3 Jahren mit GnRH-Analoga kombiniert werden. Eine Monotherapie mit GnRHa oder Aromatasehemmern $(\mathrm{AH})$ sollte vermieden werden. Der Einsatz von $\mathrm{GnRHa}$ in Kombination mit $\mathrm{AH}$ ist jedoch Gegenstand klinischer Studien. Die adjuvante endokrine Therapie der postmenopausalen Frau mit endokrin sensitivem Mammakarzinom sollte einen $\mathrm{AH}$ beinhalten. Jedoch sind weder der optimale Zeitpunkt noch die optimale Dauer der AH-Therapie geklärt. Therapieoptionen umfassen i) 5 Jahre Anastrozol oder Letrozol anstelle von Tamoxifen, ii) nach 2-3-jähriger Behandlung mit Tamoxifen Wechsel auf Exemestan oder Anastrozol für den Rest der 5 Jahre, oder iii) nach Abschluss einer 5-jährigen Behandlung mit Tamoxifen sequentielle Gabe von Letrozol für 5 Jahre. Späte Folgen der AH-Therapie inklusive Osteoporose und Frakturen sind zu bedenken.

\footnotetext{
*As members of the Breast Commission, part of the AGO (Working Group Gynecologic Oncology, German Society of Obstetrics and Gynecology)
}

\begin{tabular}{ll}
\hline KARGER & ( ) 2006 S. Karger GmbH, Freiburg \\
Fax +497614520714 & Accessible online at: \\
$\begin{array}{l}\text { E-mail Information@Karger.de } \\
\text { www.karger.com }\end{array}$ & www.karger.com/brc
\end{tabular}




\section{Adjuvant Endocrine Therapy in Premenopausal Patients}

Estrogen receptor (ER) antagonism alone or in combination with luteinizing hormone-releasing hormone agonists (LHRHa) as ovarian ablation (OA) are currently accepted endocrine treatment strategies for premenopausal women with hormone-sensitive breast cancers. The trophic effect of estrogens on hormone-responsive breast tumors enables treatment strategies that either inhibit the production of endogenous estrogens or block their effects at the ER to be employed. In premenopausal women, the ovaries are the main source of systemic estrogen, therefore OA has been an established and accepted treatment for premenopausal women with hormone receptor-positive breast cancer since first being reported by Beatson more than 100 years ago [1]. As an alternative to OA, the ER can be blocked using the selective ER modulator tamoxifen which acts as an anti-estrogen in breast tumors. Tamoxifen has been the mainstay of endocrine therapy for almost 30 years, and has significantly increased survival both alone and in combination with chemotherapy or OA in the premenopausal setting, and as monotherapy in the postmenopausal setting [2].

\section{Current Endocrine Treatment Options for Premenopausal Women with Breast Cancer}

\section{Tamoxifen}

The Early Breast Cancer Trialists' Collaborative Group metaanalysis of clinical trials comparing adjuvant tamoxifen (approximately 5 years) with no tamoxifen revealed substantial reductions in recurrence for women aged 40-49 years and significant reductions for those aged 50-59 years. These reductions were comparable with those in the group as a whole [2]. For women aged $<50$ years with hormone receptor-positive breast cancer, tamoxifen treatment resulted in a $32 \%$-reduction in the mortality risk. However, long-term exposure to tamoxifen has been associated with an increased risk of endometrial cancer and thromboembolic events as a result of the agonist properties of tamoxifen [2]. Tamoxifen has also been found to be less effective in patients overexpressing the human epidermal growth factor receptor 2 (HER2) gene, which is associated with lower ER expression [3]. As reported recently by the International Breast Cancer Study Group (IBCSG Trial 13-93), tamoxifen after adjuvant chemotherapy significantly improved treatment outcome in premenopausal patients with endocrine-responsive disease, but its use in patients with ER-negative tumors is not recommended [4].

\section{LHRHa}

Efficacy of the LHRHa goserelin in the treatment of premenopausal patients with early breast cancer has been demonstrated in the 'Zoladex' Early Breast Cancer Research Association (ZEBRA) Trial [5]. At a median follow-up of
7.3 years, goserelin (2-year treatment) was equivalent to CMF (cyclophosphamide, methotrexate and 5-fluorouracil; 6 cycles) for disease-free survival (DFS), and was non-inferior to CMF for overall survival (OS) in patients with ER-positive, lymph node-positive tumors [6]. Similar findings for ER-positive, lymph node-negative breast cancer emerged from the International Breast Cancer Study Group Trial VIII (IBCSG VIII), where in pre- or perimenopausal patients DFS was similar for patients receiving either CMF (6 cycles) alone or goserelin (24 months) alone. Sequential therapy with goserelin following 6 cycles of CMF provided numerically superior DFS compared with either treatment alone, primarily because of the results in younger women [7]. More recently, the Eastern Cooperative Oncology Group (ECOG) E5188 Trial (or INT 0101) has noted that the administration of a 5-year goserelin therapy following 6 cycles of CAF (cyclophosphamide, doxorubicin, 5-fluorouracil) improves 9-year DFS to a greater extent for women $<40$ years of age ( 48 and $58 \%$ for CAF alone and CAF plus goserelin, respectively) than for women $\geq 40$ years of age (61 and $62 \%$ for CAF alone and CAF plus goserelin, respectively) [8].

\section{LHRHa plus Tamoxifen}

Combining medical OA with tamoxifen is a logical strategy in premenopausal women with hormone-responsive breast cancer. This is based on the fact that endocrinologically there is a slightly increased suppression of FSH and estradiol using OA with tamoxifen compared with using OA alone [9]. In a larger study of goserelin plus tamoxifen versus goserelin alone, a significant difference in objective response (OR) and progression-free survival (PFS), but not OS, was reported [10]. The lack of a difference in OS is most probably due to the fact that in the latter study, the design in the control (goserelin alone) arm was to give sequential tamoxifen at the investigator's discretion after progression on goserelin alone, and thereby improve the survival chances of some of the patients who progressed on control therapy.

The significant benefit of adding goserelin with or without tamoxifen to standard therapy (including radiotherapy and/or chemotherapy) in the adjuvant setting has been confirmed in the 'Zoladex' in Premenopausal Patients (ZIPP) meta-analysis [11]. Also in the adjuvant setting, combination therapy has been compared with standard CMF therapy for the treatment of premenopausal women with early breast cancer $[12,13]$. In the Austrian Breast and Colorectal Cancer Study Group (ABCSG) Trial 05, goserelin plus tamoxifen was significantly more effective than CMF with respect to relapse-free and local recurrence-free survival in 1,034 premenopausal patients with ER-positive tumors at a median follow-up of 5 years [13]. In the Italian Breast Cancer Adjuvant Chemo-Hormone Therapy Cooperative Group Trial (GROCTA 02), at a median follow-up of 6.3 years, no significant differences in terms of OS or DFS were reported between chemotherapy and combined endocrine therapy (OA via goserelin for 2 years, ovari- 
Fig. 1. AGO

Recommendation 2006 on chemoendocrine treatment of premenopausal patients with endocrine-responsive tumors (I) [15]. LOE: level of evidence; GR: grade of recommendation; Tam: tamoxifen.

Fig. 2. AGO Recommendation 2006 on chemoendocrine treatment of premenopausal patients with endocrine-responsive tumors (II) [15]. LOE: level of evidence; GR: grade of recommendation; Tam: tamoxifen, AI: aromatase inhibitors.

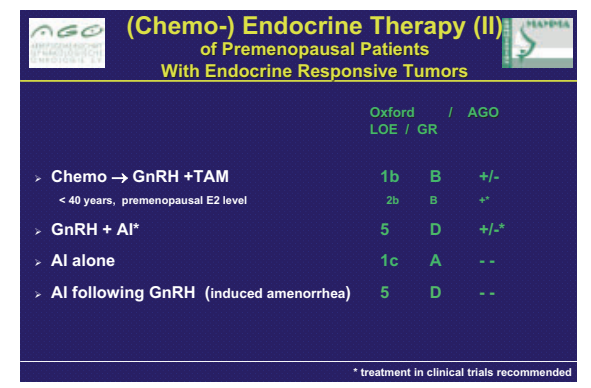

Fig. 3. AGO Recommendation 2006 on endocrine treatment of premenopausal patients with endocrine-responsive tumors: treatment duration [15]. LOE: level of evidence; GR: grade of recommendation; Tam: tamoxifen, AI: aromatase inhibitors.

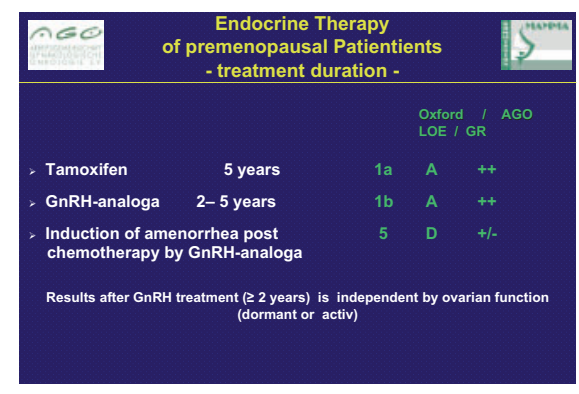

Fig. 4. Chemotherapy-induced amenorrhea (CIA).

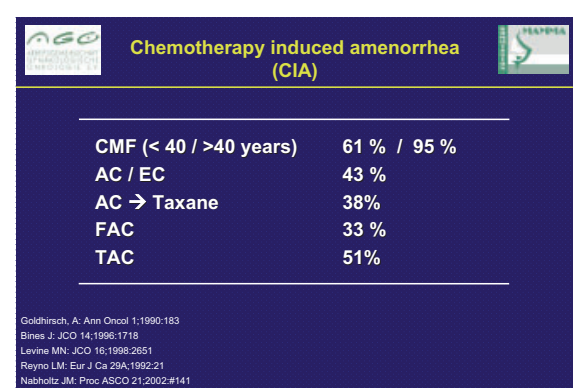

an irradiation, or oophorectomy plus 5 years tamoxifen) [14]. However, this study included only 244 patients and was therefore underpowered (compared with ABCSG Trial 05) to show a difference.

These trials demonstrate that combination endocrine therapy with LHRHa plus tamoxifen is an effective endocrine treatment that is at least comparable to, and in the case of ABCSG Trial 05 better than, standard CMF chemotherapy for premenopausal women with hormone receptor-positive early breast cancer. The current German Working Group guidelines also support the use of combination therapy with LHRHa plus tamoxifen [15], as well as the current St. Gallen consensus recommendations [16] (fig.1-3).

\section{The Future of Endocrine Therapy in Premenopausal Women: Combination Therapy with an LHRHa plus an Aromatase Inhibitor $(A I)$}

Several ongoing clinical trials are currently investigating different combinations of LHRHa, AI and tamoxifen therapy to define the most suitable adjuvant endocrine treatment strategy (table 1). Many of these trials were initiated before the publication of efficacy data for the LHRHa plus AI combination in advanced disease, illustrating the general acceptance of the rationale behind this combination therapy approach in premenopausal women. This strategy is, of course, directed towards endocrine-responsive disease. The effect of other factors, such as HER2 overexpression, also requires clarification. Due to the current lack of randomized phase III trial data, treatment guidelines, including those of ASCO, the NCCN and the German Working Group, agree that premenopausal women should not receive AIs outside of the context of clinical trials $[15,17,18]$.

The Premenopausal Optimal Management Is Endocrine Therapy (PROMISE) Trial is studying the effect of adding chemotherapy to adjuvant treatment with goserelin plus anastrozole (with or without radiotherapy). The Suppression of Ovarian Function Trial (SOFT) and Tamoxifen and Exemestane Trial (TEXT) are comparing OA plus tamoxifen (with or without chemotherapy) with OA plus exemestane (with or without chemotherapy). The Premenopausal Endocrine Responsive Chemotherapy Trial (PERCHE) is a 4-arm trial comparing OA plus tamoxifen with OA plus exemestane (with or without chemotherapy). However, although data relating to such a variety of treatment strategies will help elucidate how best to treat premenopausal women with early breast cancer, results from these trials are not expected for about 10 years. To date, data describing the activity of targeted therapies in combination with optimized endocrine blockade in premenopausal women are lacking and urgently needed. For example, while HER2 overexpression is considered to be indicative of tamoxifen resistance in postmenopausal women, there are no data to show that the same is true for premenopausal women treated with LHRHa plus an AI. Consequently, there exists a small subgroup of premenopausal patients with endocrine-responsive disease and HER2 overexpression, who may be adequately treated with goserelin plus an AI plus trastuzumab. Currently, all large trials investigating trastuzumab have been performed in combination with, or following, cytostatic treatment, thereby leaving this important question unanswered [19, 20]. The same may be true for other targeted therapies. 
Table 1. Active and ongoing trials of adjuvant AI therapy in premenopausal women with early breast cancer

\begin{tabular}{|c|c|}
\hline Trial name & Therapy arms \\
\hline ABCSG Trial $12^{\mathrm{a}}$ & $\begin{array}{l}\text { goserelin plus anastrozole }( \pm \text { zoledronic acid }) \text { vs. gosere- } \\
\text { lin plus tamoxifen ( } \pm \text { zoledronic acid })\end{array}$ \\
\hline Premenopausal Optimal Management & immediate goserelin plus anastrozole vs. chemotherapy \\
\hline Is Endocrine Therapy (PROMISE) ${ }^{\mathrm{b}}$ & followed by goserelin plus anastrozole \\
\hline $\begin{array}{l}\text { Suppression of Ovarian Function Trial } \\
(\text { SOFT })^{\mathrm{b}}\end{array}$ & $\begin{array}{l}\text { tamoxifen monotherapy vs. OFS plus tamoxifen vs. OFS } \\
\text { plus exemestane (each arm } \pm \text { chemotherapy) }\end{array}$ \\
\hline $\begin{array}{l}\text { Tamoxifen and Exemestane Trial } \\
(\mathrm{TEXT})^{\mathrm{b}}\end{array}$ & $\begin{array}{l}\text { OFS plus tamoxifen or exemestane vs. chemotherapy } \\
\text { plus OFS plus tamoxifen or exemestane }\end{array}$ \\
\hline Premenopausal Endocrine Responsive & triptorelin plus tamoxifen vs. triptorelin plus exemestane \\
\hline Chemotherapy Trial (PERCHE) $)^{\mathrm{b}}$ & (both arms \pm chemotherapy) \\
\hline
\end{tabular}

${ }^{a}$ Endocrine therapy given for 3 years.

${ }^{b}$ Endocrine therapy given for 5 years.

OFS $=$ Ovarian function suppression
Clinical Relevance of Induced Amenorrhea in Premenopausal Patients

Since in the premenopausal setting, there are 2 options for inducing amenorrhea - either by ovarian ablation itself or as a result of a given chemotherapy, known as chemotherapy-induced amenorrhea (CIA) - there is still an ongoing discussion on the issue of the duration of amenorrhea. In discussing individual treatment options, physician and patients might be aware of the rate of CIA (fig. 4). In general, the evidence available so far is suggesting that the duration of amenorrhea, if reversible at all, might be in the timeframe of $2-5$ years. More specifically, this treatment option should be offered to very young women under the age of 40 years. It is of specific interest as a result of the IBCSG 13-93 trial in node-positive breast cancer patients, that patients with ER-positive tumors who achieved CIA had a significantly improved outcome (hazard ratio (HR) for amenorrhea vs. no amenorrhea $=0.61$; $95 \% \mathrm{CI}=0.44-0.86 ; \mathrm{p}=0.004)$, regardless of whether they received tamoxifen [18]. If after induction of CIA the treatment with AIs might be an option is still to be clarified in clinical trials and should be avoided in clinical routine at this time. Besides, treatment-induced toxicity, affecting e.g. bone mineral density, should be properly monitored to avoid long-term morbidity.

\section{Adjuvant Endocrine Therapy in Postmenopausal Patients}

Adjuvant tamoxifen therapy for 5 years improves DFS and OS in patients with hormone-sensitive primary breast cancer [2]. However, not every patient responds to tamoxifen, and adverse events, such as hot flushes, thromboembolism and endometrial cancer risk, limit its use. Thus, the AIs anastrozole, letrozole and exemestane - agents with a better benefit-risk ratio in patients with metastatic breast cancer as compared to tamoxifen - have been evaluated against tamoxifen in large clinical phase III trials in the adjuvant setting. Over the last 3 years, the results of 5 large trials (ATAC, BIG 1-98, IES, ARNO 95/ABCSG 8, MA.17) suggested that, in a postmenopausal woman requiring adjuvant hormonal therapy, i) tamoxifen should be replaced by anastrozole or letrozole, ii) tamoxifen should be switched to exemestane or anastrozole after 2-3 years of therapy, and iii) after 5 years of tamoxifen extended endocrine treatment with letrozole for at least 3 years should be initiated [21-25].

\section{Upfront Therapy with Anastrozole or Letrozole}

ATAC [21] compared anastrozole with tamoxifen for 5 years in 6,241 postmenopausal women with localized breast cancer following complete tumor resection. After a median followup of 68 months, anastrozole significantly prolonged DFS (HR 0.87, p = 0.01), time to recurrence (TTR; HR 0.79, $\mathrm{p}<0.001$ ), time to distant recurrence (TTDR; HR 0.86, $\mathrm{p}=0.04$ ), and incidence of contralateral breast cancers (HR $0.58, \mathrm{p}=0.01)$. An even greater advantage was seen in DFS (HR 0.83, p = 0.005) and TTR (HR 0.74, p = 0.0002) in hormone receptor positive patients. Anastrozole was also associated with fewer side effects than tamoxifen, especially gynaecological problems and vascular events, but arthralgia and fractures were increased. OS was similar for the anastrozole and the tamoxifen group (HR 0.97, $\mathrm{p}=0.7$ ).

The BIG 1-98 study compared letrozole with tamoxifen in 8,010 women with endocrine responsive primary breast cancer [22]. After a median follow-up of 26 months, letrozole significantly improved DFS (HR 0.81, p = 0.003) and TTDR (HR $0.73, \mathrm{p}=0.001)$. According to a prospectively planned subgroup analysis, letrozole demonstrated even greater benefit than tamoxifen in high-risk patients treated with adjuvant chemotherapy. Thromboembolism, endometrial cancer and vaginal bleeding were more common in the tamoxifen group. Women given letrozole had a higher incidence of skeletal and cardiac events and of hypercholesterolemia. The BIG 1-98 trial also had 2 sequential arms, but there are no data from this arms available yet. 


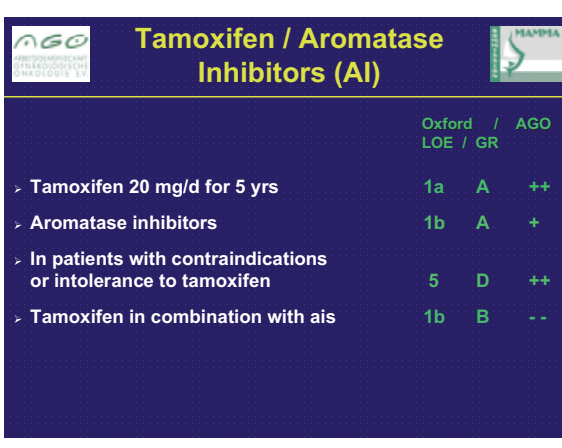

Fig. 5. Levels of evidence (LOE) for endocrine adjuvant treatment in postmenopausal women.

Fig. 6. Duration and sequencing of endocrine adjuvant treatment in postmenopausal women.

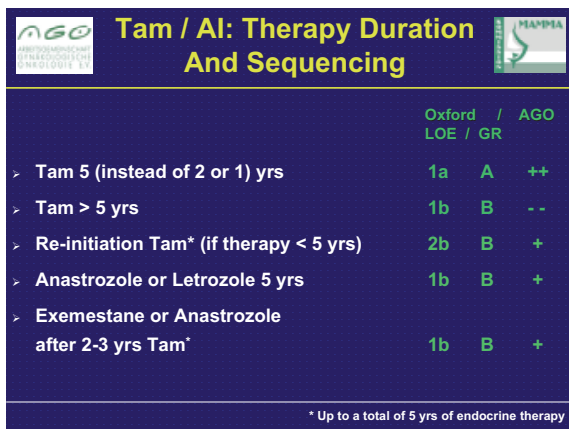

Switch to Exemestane or Anastrozole after 2-3 Years of Tamoxifen

The IES trial tested in 4,742 patients with endocrine responsive primary breast cancer whether, after 2-3 years of tamoxifen therapy, switching to exemestane was more effective than continuing tamoxifen therapy for the remainder of the 5 years of treatment [23]. After a median follow-up of 31 months, switching to exemestane resulted in a significant improvement in DFS (HR 0.68, $\mathrm{p}<0.001$ ), distant DFS (DDFS; HR 0.66, $\mathrm{p}<0.001$ ), and risk of contralateral breast cancer (HR 0.44 , $\mathrm{p}=0.04)$. OS was not significantly different in the 2 groups. Severe toxic effects of exemestane were rare.

ARNO 95 and ABCSG 8, 2 prospective trials with nearly identical inclusion criteria, evaluated 3,224 postmenopausal women with hormone-sensitive early breast cancer who had completed 2 years of tamoxifen and were randomized to receive anastrozole or tamoxifen for the remainder of their 5-year adjuvant therapy [24]. A retrospectively planned combined analysis with a median follow-up of 28 months found a significant decrease in the risk of an event occurring in the anastrozole group as compared with the tamoxifen group (HR 0.60, $\mathrm{p}<0.001$ ). Both study treatments were well tolerated. There were significantly more fractures but fewer thromboses in patients treated with anastrozole. A recent update of ARNO 95 with 30 months of median follow-up as well as a meta-analysis considering all 3 sequential trials with anastrozole (ARNO 95, ABCSG 8, ITA) reported a significantly improved OS for patients who switched to anastrozole after 2-3 years of tamoxifen therapy [26]. However, these analyses have been reported in abstract form only, and there was a considerable amount of heterogeneity within individual trials regarding OS.

\section{Extended Adjuvant Endocrine Therapy with Letrozole}

The MA.17 trial, which was designed to determine whether extended adjuvant therapy with letrozole after 5 years of tamoxifen in 5,187 postmenopausal patients with hormone-sensitive breast cancer reduces the risk of recurrence, was stopped early after an interim analysis showed that letrozole improved DFS [25]. After a median follow-up of 30 months, women in the letrozole arm had statistically significantly better DFS (HR 0.58, p < 0.001) and DDFS (HR 0.60, p = 0.002). OS was the same in both arms (HR 0.82, p = 0.3). However, among patients with axillary lymph node metastases, OS was significantly improved with letrozole $(\mathrm{HR}=0.61, \mathrm{p}=0.04)$. The incidence of contralateral breast cancer was lower in women receiving letrozole, but the difference was not statistically significant. Women receiving letrozole experienced more hormone-related side effects than those receiving placebo, but the incidences of bone fractures and cardiovascular events were the same. In order to evaluate the optimal duration of extended adjuvant treatment, a retrospective analysis of the MA.17 trial data prior to unblinding was performed. HRs of DFS for letrozole relative to placebo showed a progressive decrease over the study period from 0.52 at 12 months to 0.19 after 48 months [27]. This decreasing trend was statistically significant $(\mathrm{p}<0.001)$, showing a larger duration of letrozole is associated with greater benefit. A similar trend was shown for DDFS ( 0.43 at 12 months to 0.21 at 48 months, $p=0.001)$. Following unblinding of the study after a median of 30 months of treatment, placebo recipients were offered the opportunity to switch to letrozole. The majority of patients $(n=1,655)$ opted to switch, while 613 patients received no further treatment. Women who decided to switch were younger, had more advanced disease, a worse performance status, and were more likely to have received adjuvant chemotherapy [28]. Despite the worse prognosis in this group, patients switching to letrozole had significantly improved DFS (HR 0.31, p < 0.001), DDFS (HR 0.28, p = 0.002), and OS (HR 0.53, p = 0.05) after a median follow-up of 54 months as compared with those who opted for no treatment. Letrozole was well tolerated with no significant difference in bone fractures or cardiovascular events, although new diagnosis of osteoporosis was significantly greater in patients on letrozole.

\section{Current Guidelines for Endocrine Adjuvant Treatment for Postmenopausal Women}

Based on these results, adjuvant therapy for postmenopausal women with endocrine responsive breast cancer should include an AI. However, neither the optimal timing nor duration of AI therapy is established (fig. 5, 6) [29]. AIs are appropriate as initial treatment for women with contraindications to tamoxifen. For all other postmenopausal women, treatment options include i) 5 years of anastrozole or letrozole treatment instead of tamoxifen, ii) sequential therapy consisting of tamoxifen for 2-3 years followed by exemestane or anastrozole for the remainder of 5 years, or iii) sequential therapy consist- 
ing of tamoxifen for 5 years followed by letrozole for 5 years. Patients intolerant of AIs should receive tamoxifen. There are no data on the use of tamoxifen after an AI in the adjuvant setting. Tamoxifen and AIs should not be used concurrently. Women with hormone receptor-negative tumors should not receive adjuvant endocrine treatment. The role of other bio- markers, such as progesterone receptor and HER2 status, in selecting optimal endocrine therapy remains controversial [ 30 , 31]. The side effect profiles of tamoxifen and AIs differ. The late consequences of AI therapy, including osteoporosis and fractures, should be considered and further characterized.

\section{References}

1 Beatson GT: On the treatment of inoperable cases of carcinoma of the mamma: suggestions for a new method of treatment, with illustrative cases. Lancet 1896;2:105-107.

$\checkmark 2$ Early Breast Cancer Trialists' Collaborative Group: Effects of chemotherapy and hormonal therapy for early breast cancer on recurrence and 15-year survival: an overview of the randomised trials. Lancet 2005:365:1687-1717.

-3 Arpino G, Green SJ, Allred DC, et al.: HER-2 amplification, HER-1 expression, and tamoxifen response in estrogen receptor-positive metastatic breast cancer: a southwest oncology group study. Clin Cancer Res 2004;10:5670-5676.

4 International Breast Cancer Study Group: Tamoxifen after adjuvant chemotherapy for premenopausal women with lymph node positive breast cancer: International Breast Cancer Study Group Trial 13-93. J Clin Oncol 2006;24:1332-1341.

5 Jonat W, Kaufmann M, Sauerbrei W, et al.: Goserelin versus cyclophosphamide, methotrexate, and fluorouracil as adjuvant therapy in premenopausal patients with node-positive breast cancer: the Zoladex Early Breast Cancer Research Association Study. J Clin Oncol 2002:20:4628-4635.

6 Kaufmann M, Jonat W, Blamey R, et al.: Survival analyses from the ZEBRA study: goserelin (Zoladex $^{\mathrm{TM}}$ ) versus $\mathrm{CMF}$ in premenopausal women with node-positive breast cancer. Eur J Cancer 2003;39:1711-1717.

7 Castiglione-Gertsch M, O’Neill A, Price KN, et al.: Adjuvant chemotherapy followed by goserelin versus either modality alone for premenopausal lymph node-negative breast cancer: a randomized trial. J Natl Cancer Inst 2003;95:1833-1846.

8 Davidson NE, O'Neill AM, Vukov AM, et al.: Chemoendocrine therapy for premenopausal women with axillary lymph node-positive, steroid hormone receptor-positive breast cancer: results from INT 0101 (E5188). J Clin Oncol 2005;23:5973-5982.

$\checkmark 9$ Robertson JF, Walker KJ, Nicholson RI, Blamey RW: Combined endocrine effects of LHRH agonist (Zoladex) and tamoxifen (Nolvadex) therapy in premenopausal women with breast cancer. $\mathrm{Br} \mathrm{J}$ Surg 1989;76:1262-1265.

10 Jonat W, Kaufmann M, Blamey RW, et al.: A randomised study to compare the effect of the luteinising hormone releasing hormone (LHRH) analogue goserelin with or without tamoxifen in pre- and perimenopausal patients with advanced breast cancer. Eur J Cancer 1995;31A:137-142.

11 Baum M, Hackshaw A, Houghton J, Rutqvist LE, Fornander T, Nordenskjold B, Nicolucci A, Sainsbury R, ZIPP, International Collaborators' Group: Adjuvant goserelin in pre-menopausal patients with early breast cancer: results from the ZIPP study. Eur J Cancer 2006;42:895-904.

12 Boccardo F, Rubagotti A, Puntoni M, et al.: Switching to anastrozole versus continued tamoxifen treatment of early breast cancer: preliminary results of the Italian Tamoxifen Anastrozole trial. J Clin Oncol 2005;23:5138-5147.
13 Jakesz R, Hausmaninger H, Kubista E, et al.: Randomized adjuvant trial of tamoxifen and goserelin versus cyclophosphamide, methotrexate, and fluorouracil: evidence for the superiority of treatment with endocrine blockade in premenopausal patients with hormone-responsive breast cancer - Austrian Breast and Colorectal Cancer Study Group Trial 5. J Clin Oncol 2002;20:4621-4627.

14 Boccardo F, Rubagotti A, Amoroso D, et al.: Cyclophosphamide, methotrexate, and fluorouracil versus tamoxifen plus ovarian suppression as adjuvant treatment of estrogen receptor-positive pre-/ perimenopausal breast cancer patients: results of the Italian Breast Cancer Adjuvant Study Group 02 randomized trial. J Clin Oncol 2000;18: 2718-2727.

15 Arbeitsgemeinschaft Gynaekologische Onkologie E.V.: AGO Guidelines 2006; www.ago-online.org.

16 Goldhirsch A, Glick JH, Gelber RD, Coates AS, Thurlimann B, Senn HJ: Meeting highlights: international expert consensus on the primary therapy of early breast cancer 2005. Ann Oncol 2005;16: 1569-1583.

17 National Comprehensive Cancer Network: NCCN Practice Guidelines in Oncology v.1,2005: Breast Cancer; www.nccn.org.

18 Winer EP, Hudis C, Burstein HJ, et al.: American Society of Clinical Oncology technology assessment on the use of aromatase inhibitors as adjuvant therapy for postmenopausal women with hormone receptor-positive breast cancer: status report 2004. J Clin Oncol 2005;23:619-629.

19 Piccart-Gebhart MJ, Procter M, Leyland-Jones B, et al.: Trastuzumab after adjuvant chemotherapy in HER2-positive breast cancer. N Engl J Med 2005; 353:1659-1672.

20 Romond EH, Perez EA, Bryant J, et al.: Trastuzumab plus adjuvant chemotherapy for operable HER2-positive breast cancer. N Engl J Med 2005;353:1673-1684.

21 ATAC Trialist's Group: Results of the ATAC (arimidex, tamoxifen, alone or in combination) trial after completion of 5 years' adjuvant treatment for breast cancer. Lancet 2005;365:60-62.

22 The Breast International Group (BIG)1-98 Collaborative Group: A comparison of letrozole and tamoxifen in postmenopausal women with early breast cancer. N Engl J Med 2005;353:2747-2757.

23 Coombes RC, Hall E, Gibson LJ, Paridaens R, Jassem J, Delozier T, Jones SE, Alvarez I, Bertelli G, Ortmann O, Coates AS, Bajetta E, Dodwell D, Coleman RE, Fallowfield LJ, Mickiewicz E, Andersen J, Lønning PE, Cocconi G, Stewart A, Stuart N, Snowdon CF, Carpentieri M, Massimini G, Bliss JM, for the Intergroup Exemestane Study: A randomized trial of exemestane after two to three years of tamoxifen therapy in postmenopausal women with primary breast cancer. N Engl J Med 2004;350:1081-1092.
24 Jakesz R, Jonat W, Gnant M, Mittlboeck M, Greil R, Tausch C, Hilfrich J, Kwasny W, Menzel C, Samonigg H, Seifert M, Gademann G, Kaufmann M, on behalf of the ABCSG and the GABG: Switching of postmenopausal women with endocrine-responsive early breast cancer to anastrozole after 2 years' adjuvant tamoxifen: combined results of ABCSG trial 8 and ARNO 95 Trial. Lancet 2005; 366:455-462.

25 Goss PE, Ingle JN, Martino S, Robert NJ, Muss HB, Piccart MJ, Castiglione M, Tu D, Shepherd LE, Pritchard KI, Livingston RB, Davidson NE, Norton L, Perez EA, Abrams JS, Cameron DA, Palmer MJ, Pater JL: Randomized trial of letrozole following tamoxifen as extended adjuvant therapy in receptor-positive breast cancer: updated findings from NCIC CTG MA.17. J Natl Cancer Inst 2005; 97:1262-1271

26 Jonat W, Gnant M, Boccardo F, Kaufmann M, Rubagotti A, Jakesz R: Switching from adjuvant tamoxifen to anastrozole in postmenopausal women with hormone-responsive early breast cancer: a meta-analysis of the ARNO 95 Trial, ABCSG Tria 8, and the ITA Trial. Breast Cancer Res Treat 2005; 94(suppl 1):S11(abstr 18).

27 Ingle JN, Goss PE, Tu D: Analysis of duration of letrozole extended adjuvant therapy as measured by hazard ratios of disease recurrence over time for patients on NCI CTG MA.17. Breast Cancer Res Treat 2005;94(suppl 1):S11(abstr 17).

28 Goss PE, Ingle JN, Palmer MJ, Shepherd LE, Tu D Updated analysis of NCI CTG MA.17 (letrozole vs. placebo to letrozole vs. placebo) post unblinding. Breast Cancer Res Treat 2005;94(suppl 1):S10(abstr 16).

29 Breast Commission of the German Working Group Gynecologic Oncology (AGO): Guideline for Diagnostics and Therapy of Breast Carcinomas, v. 2006; www.ago-online.org/leitlinien/2-2-1.pdf.

30 Dowsett M, Cuzick J, Wale C, Howell T, Houghton J, Baum M: Retrospective analysis of time to recurrence in the ATAC trial according to hormone receptor status: an hypothesis-generating study. J Clin Oncol 2005;23:7512-7517.

31 Viale G, Regan M, Dell'Orto P, Del Curto B, Braye S, Orosz Z, Brown R, Olszewski WP, Knox F, Oehlschlegel C, Thürlimann B: Central review of ER, PgR and HER-2 in BIG 1-98 evaluating letrozole vs. tamoxifen as adjuvant endocrine therapy for postmenopausal women with receptor-positive breast cancer. Breast Cancer Res Treat 2005;94 (suppl 1):(abstr 44). 